\title{
Ekstraksi Glukomanan dari Umbi Gembili (Dioscorea esculenta L.)
}

\section{[Extraction of Glucomannan from Gembili Bulbs (Dioscorea esculenta L.)]}

\author{
Pratiwi Listyana Sareu*, Nurhaeni, Ahmad Ridhay, Moh. Mirzan, Syamsuddin \\ Program Studi S1 Kimia Fakultas MIPA Universitas Tadulako, Indonesia
}

\begin{abstract}
Gembili bulbs (Dioscorea esculenta L.) have a fairly high carbohydrate content, so they can potentially be a new source of glucomannan compounds. This study aims to determine the yield and glucomannan characteristics of Gembili bulbs at different extraction times and temperatures. Glucomannan was obtained by extraction with water at temperatures of $45,60,75,90$, and $105^{\circ} \mathrm{C}$ for $45,60,75,90$, and 105 minutes, and precipitated with isopropyl alcohol. The results showed that the highest yield was obtained at the extraction time of 90 minutes and a temperature of $105^{\circ} \mathrm{C}$ of $53.09 \%$. The glucomannan of Gembili bulb has a molecular weight of $1,865 \times 10^{4} \mathrm{~g} / \mathrm{mol}$ with ash and water content values of $0.866 \%$ and $10.45 \%$, respectively. The results of identification of functional groups with an FTIR spectrophotometer showed that there was a functional group stretching vibration of glucomannan compounds, including the $-\mathrm{OH}$ group at a wavenumber of $3431 \mathrm{~cm}^{-1}$ and $-\mathrm{C}$ O-C (glycosidic bond) at a wavenumber of $1020.34 \mathrm{~cm}^{-1}$ and bending vibration of $-\mathrm{CH}$ functional groups on wavenumber of $850.61 \mathrm{~cm}^{-1}$.
\end{abstract}

Keywords: Glucomannan, gembili bulbs, extraction times and temperatures.

Abstrak. Umbi gembili (Dioscorea esculenta L.) memiliki kandungan karbohidrat yang cukup tinggi, sehingga dapat berpotensi sebagi sumber baru dari senyawa glukomanan. Penelitian ini bertujuan untuk mengetahui rendemen dan karakteristik glukomanan dari umbi gembili pada berbabagi waktu dan suhu ekstraksi. Glukomanan didapatkan melalui ekstraksi dengan air pada waktu 45, 60, 75, 90 dan 105 menit dan suhu 45, 60, 75, 90 dan $105^{\circ} \mathrm{C}$ serta diendapkan dengan isopropil alkohol. Hasil penelitian menunjukan rendemen tertinggi diperoleh pada waktu ekstraksi 90 menit dan suhu $105^{\circ} \mathrm{C}$, yaitu 53,09\%. Glukomanan umbi gembili memiliki berat molekul 1,865 x $10^{4}$ $\mathrm{g} / \mathrm{mol}$ dengan nilai kadar abu dan kadar air, masing-masing $0,866 \%$ dan $10,45 \%$. Hasil identifikasi gugus fungsi dengan spektofotometer FTIR menunjukkan adanya vibrasi ulur gugus fungsi senyawa glukomanan, meliputi gugus $-\mathrm{OH}$ pada bilang gelombang $3431 \mathrm{~cm}^{-1}$ dan C-O-C (ikatan glikosidik) pada bilangan gelombang 1020,34 $\mathrm{cm}^{-1}$ serta vibrasi tekuk gugus fungsi $-\mathrm{CH}$ pada bilangan gelombang $850,61 \mathrm{~cm}^{-1}$.

Kata Kunci: Glukomanan, umbi gembili, waktu dan suhu ekstraksi.

Diterima: 21 Februari 2019, Disetujui: 11 April 2021

Sitasi: Sareu, P. L., Nurhaeni., Ridhay, A., Mirzan, M., \& Syamsuddin. (2021). Ekstraksi Glukomanan dari Umbi Gembili (Dioscorea esculenta L.). KOVALEN: Jurnal Riset Kimia, 7(1): 51-58.

\section{LATAR BELAKANG}

\section{Gembili (Dioscorea esculenta L.)} merupakan suatu jenis umbi minor yang memilki kandungan karbohidrat total $27-30 \%$,

\footnotetext{
* Corresponding author

E-mail: Pratiwi_sareu@yahoo.com
}

yang terdiri $85.8 \%$ senyawa amilopektin dan $14.2 \%$ senyawa amilosa. Kandungan gula sederhana pada umbi gembili meliputi glukosa dan fruktosa dengan kadar pada kisaran 7 hingga $11 \%$ dari berat pati umbi (Rukmini \& Santosa, 2019). Menurut Prabowo et al. (2014), 
umbi gembili mengandung karbohidrat tinggi sehingga dapat dimanfaatkan sebagai tepung umbi, pati dan tepung komposit serta mengandung senyawa bioaktif yang baik untuk kesehatan. Sabda et al. (2019) menyatakan bahwa kandungan terbesar dari umbi gembili adalah karbohidrat yaitu sebesar 22,531,3\%\%. Menurut Herlina (2012), umbi gembili memiliki kandungan pati dan serat yang tinggi.

Glukomanan adalah polisakarida yang tersusun dari monomer D-glukosa $\pm 33 \%$ dan Dmannosa $\pm 67 \%$. Glukomanan banyak dimanfaatkan pada industri edible film, industry makanan, cat, kosmetik, obat-obatan, bahan perekat, dan lain-lain. Glukomanan merupakan senyawa karbohidrat yang memiliki karakteristik yang khas dari selulosa dan galaktomanan, sehingga sangat banyak dimanfaatkan pada berbagai industri (Towaha \& Rusli, 2016).

Hasil dari beberapa penelitian tentang rendemen glukomanan menunjukan hasil yang berbeda terhadap rendemen yang diperoleh baik dari suhu yang digunakan dan waktu ekstraksi. Menurut Saputro et al. (2014), waktu terbaik untuk mengestraksi glukomanan dari umbi porang adalah 30 menit, rasio jumlah bahan dengan pelarut adalah 1:15 dan suhu yang digunakan yaitu $60^{\circ} \mathrm{C}$ dengan rendemen glukomanan yang diperoleh sebesar 64,22\%. Harijati et al. (2013) melaporkan bahwa suhu ekstraksi glukomanan dari umbi porang yaitu $55^{\circ} \mathrm{C}$ dengan rendemen glukomanan sebesar 63,1\%. Dari hasil penelitian-penelitian diatas, maka perlu dilakukan penelitian lebih lanjut untuk mengetahui kondisi terbaik dalam memperoleh rendemen dan karakteristik glukomanan dari umbi gembili.

\section{METODE PENELITIAN}

\section{Bahan dan Peralatan}

Bahan digunakan meliputi umbi gembili, aquadest, etanol 95\%, isopropil alkohol, $\mathrm{NaOH}$ $10 \%, \mathrm{HCl} 2 \%$, fenilhidrazin hidroklorida, Naasetat dan arang aktif.

Peralatan yang digunakan berupa blender, hot plate (Wise Stir MSH 20-D), neraca analitik (Adventurer ohaus), oven, desikator, homogenizer kecepatan 0-3000 rpm, cawan porselen, tanur, sentrifugasi, spektrofotometer FTIR (FT-IR Spectrophotometer 8201PC Shimadzu), dan viskometer Ostwald.

\section{Prosedur Penelitian}

\section{Ekstraksi glukomanan (modifikasi metode Saputro et al., 2014)}

Umbi gembili dipisahkan dari kulitnya dan dicuci dengan air mengalir hingga bersih. Umbi gembili selanjutnya diiris tipis dengan ketebalan 0,7-1 cm dan di keringkan dibawah sinar matahari hingga kering (mudah dihancurkan), kemudian dihaluskan dengan blender dan diayak pada ukuran 60 mesh hingga diperoleh tepung umbi gembili. Tepung umbi gembili ditimbang sebanyak $20 \mathrm{~g}$ dicampurkan dengan aquadest dalam erlenmeyer pada perbandingan 1:30 (b/v), kemudian diaduk menggunakan homogenizer berkecepatan konstan 73,30 rad/s pada suhu $45,60,75,90$ dan $105^{\circ} \mathrm{C}$ selama 45, 60, 75, 90 dan 105 menit. Setelah itu, disentrifugasi dengan kecepatan 314,16 rad/s selama 15 menit kemudian disaring dan filtrat yang diperoleh dipekatkan hingga setengah volume awal. Filtrat pekat ditambahkan isopropil alkohol 95\% dengan perbandingan 1:15 (b/v) sambil diaduk. Endapan yang terbentuk disaring, selanjutnya dicuci dengan etanol 95\% dan dikeringkan dalam oven pada suhu $40{ }^{\circ} \mathrm{C}$ 
selama 24 jam. Glukomanan yang didapatkan, selanjutnya ditentukan rendemen dan dianalisis gugus fungsinya dengan menggunakan Spektrofotometer FTIR.

\section{Penentuan kadar glukomanan umbi gembili}

Satu gram tepung umbi gembili dimasukkan ke dalam erlenmeyer dan ditambahkan $50 \mathrm{ml} \mathrm{HCl} \mathrm{2 \%}$. Pada erlenmeyer dipasang pendingin balik dan dididihkan selama tiga jam, kemudian didinginkan dan disaring. Filtrat yang diperoleh, dinetralkan dengan $\mathrm{NaOH}$ $10 \%$, kemudian ditambahkan arang aktif untuk menghilangkan warna. Filtrat dipekatkan sampai volume $10 \mathrm{ml}$ dan ditambahkan 0,4 gram fenilhidrazin hidroklorida dan 0,65gram $\mathrm{Na}$ asetat dalam $5 \mathrm{ml}$ aquades. Campuran disimpan dalam lemari es selama 24 jam. Kristal mannosa fenilhidrazin disaring, dikeringkan pada suhu kamar, lalu ditimbang (Ohtsuki, 1967).

\section{Karakterisasi glukomanan}

Glukomanan umbi gembili dikarakterisasi meliputi kadar air, kadar abu, dan berat molekul. Penentuan kadar air menggunakan metode gravimetrik (AOAC, 2005). Kadar abu glukomanan dari tepung umbi gembili juga ditentukan dengan cara gravimetri (AOAC, 2005). Berat molekul glukomanan ditentukan dengan menggunakan alat viskometer oswald. Larutan glukomanan dengan konsentrasi 0,0 ; 0,002; 0,004; 0,006; 0,008; dan 0,01 g/mL aquadest disiapkan. Setiap konsentrasi ditentukan waktu alirnya melalui pengukuran berulang dengan menggunakan viskometer oswald.

\section{HASIL DAN PEMBAHASAN}

\section{Waktu Ekstraksi Glukomanan dari Tepung Umbi Gembili}

Waktu ekstraksi yang digunakan yaitu 45 menit, 60 menit, 75 menit, 90 menit dan 105 menit dengan suhu $45^{\circ} \mathrm{C}$ dengan rendemen glukomanan berturut-turut yaitu $11,15 \%$; 14,7\%; 18,25\%; 23,93\% dan 23,13\% (Gambar 1). Rendemen glukomanan yang dihasilkan dari penelitian ini berkorelasi positif dengan meningkatnya waktu ekstraksi. Waktu ekstraksi terbaik berdasarkan variasi waktu ekstraksi yang diterapkan adalah 90 menit dengan rendemen sebesar $23,93 \%$.

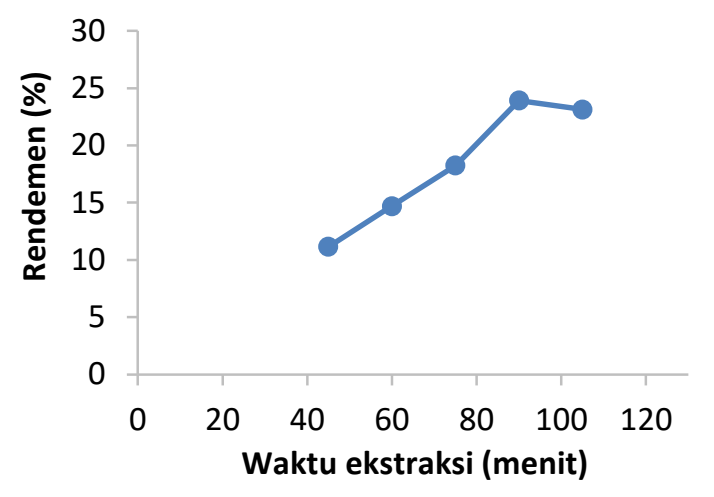

Gambar 1. Hubungan waktu ekstraksi terhadap rendemen glukomanan

Rendemen glukomanan dari umbi gembili mengalami peningkatan pada waktu ekstraksi 45 menit sampai 90 menit (Gambar 1). Meningkatnya rendemen glukomanan disebabkan karena waktu ekstraksi yang semakin akan menyebabkan waktu kontak antara tepung umbi gembili dan pelarut akan semakin lama sehingga lebih banyak interaksi yang terjadi, namun pada waktu ekstraksi 90 menit sampai 105 menit hasil rendemen yang diperoleh cenderung stabil. Saputro et al. (2014) mendapatkan waktu ekstraksi terbaik glukomanan pada umbi porang adalah 30 menit dengan rendemen sebesar $64,22 \%$. Selain itu, Anindita et al. (2016) melaporkan bahwa waktu ekstraksi terbaik pada glukomanan tepung biji salak yaitu 150 menit dengan rendemen sebesar $21,57 \%$.

Hasil analisis sidik ragam pada taraf kepercayaan $95 \%(\alpha=0,05)$, diperoleh nilai 
signifikan < a yang berarti bahwa waktu ekstraksi berpengaruh nyata terhadap rendemen glukomanan. Hasil uji lanjut Duncan menunjukan bahwa waktu ekstraksi 45 menit, 60 menit dan 75 menit berbeda nyata satu sama lain, sedangkan waktu ekstraksi 90 menit dan 105 menit berbeda tidak nyata. Berdasarkan olah data tersebut, maka waktu ekstraksi glukomanan umbi gembili terpilih adalah 90 menit.

\section{Suhu Ekstraksi Glukomanan dari Tepung Umbi Gembili}

Suhu ekstraksi berpengaruh pada glukomanan dari tepung umbi gembili, maka diterapkan variasi suhu ekstraksi agar menghasilkan rendemen glukomanan tertinggi. Grafik menunjukan bahwa suhu ekstraksi terbaik berdasarkan variasi suhu yang diterapkan adalah suhu $105^{\circ} \mathrm{C}$ dengan rendemen sebesar 53,09\% (Gambar 2). Hal ini menunjukan bahwa rendemen yang dihasilkan berkolerasi positif dengan meningkatnya suhu ekstraksi.

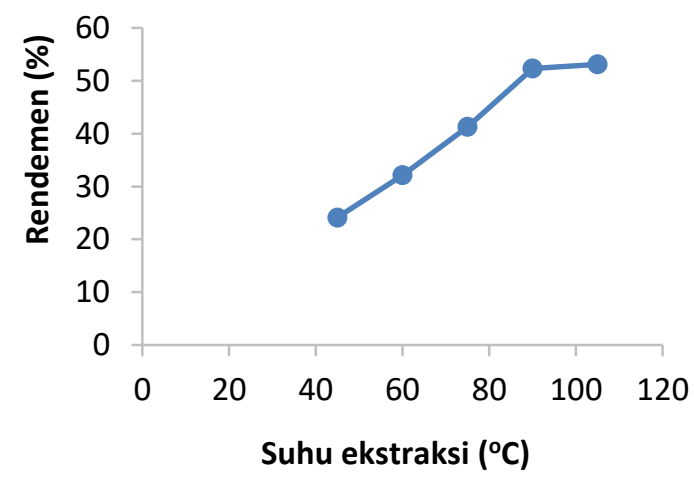

Gambar 2. Hubungan suhu ekstraksi terhadap rendemen glukomanan

Rendemen glukomanan mengalami peningkatan dengan meningkatnya suhu ekstraksi (Gambar 2). Meningkatnya suhu ekstraksi berbanding lurus dengan rendemen gluokoman karena ketika tepung dilarutkan, maka akan memberikan ukuran partikel yang lebih mudah mengendap sehingga glukomanan yang diperoleh akan meningkat (Rohimi \& Ninghidayati, 2013). Tatirat \& Charoenrein (2011) melakukan ekstraksi dari tepung konjak dan mendapatkan hasil rendemen glukomanan tertinggi pada penggunaan suhu $75^{\circ} \mathrm{C}$ dengan rendemen sebesar $35,41 \%$.

Pada peneltian terdahulu, ekstraksi umbi porang (Amorphophallus paeniifolius (Dennst.) Nicolson) menggunakan suhu ekstraksi $95^{\circ} \mathrm{C}$ menghasilkan rendemen glukomanan sebesar 41,61\% (Setiawati et al., 2017). Sementara itu, Harijati et al., (2013) melaporkan bahwa suhu ekstraksi glukomanan terbaik dari umbi porang adalah $55^{\circ} \mathrm{C}$ dengan rendemen glukomanan $63,1 \%$.

Hasil analisis sidik ragam (taraf kepercayaan 95\% $(\alpha=0,05))$ menunjukan bahwa suhu ekstraksi berpengaruh nyata terhadap rendemen glukomanan (nilai $p<\alpha$ ). Hasil uji lanjut Duncan menunjukan bahwa semua perlakuan suhu berbeda nyata.

\section{Kadar Glukomanan Umbi Gembili}

Pengukuran kadar glukomanan dilakukan dengan metode fenilhidrazin dan didapatkan . kadar glukomanan 39,49\%. Hasil yang diperoleh lebih baik dibandingkan penelitian Akbar et al., (2013) yang mendapatkan 30,56\% glukomanan dari tepung konjak dengan metode fenilhidrazin. Penggunaan fenilhidrazin berfungsi sebagai pengikat manosa. Prinsip uji fenilhidrazin, yaitu gugus karbonil dari aldosa dan ketosa dalam glukomanan akan bereaksi dengan fenilhidrazin dan membentuk senyawa osazon yang berwarna kuning jingga.

Hasil yang diperoleh masih lebih rendah dari pada kadar glukomanan tepung konjak, yaitu 63,49\% (Widjanarko \& Megawati, 2015). (Wigoeno et al., 2013) juga mendapatkan kadar 
glukomanan yang lebih tinggi $(50,84 \%)$ dari umbi porang. Perbedaan kadar glukomanan dari tumbuhan disebebkan oleh beberapa faktor, antara lain kadar serat, kadar pati, dan kadar oksalat. Apabila kadar glukomanan meningkat, maka akan diimbangi dengan komponen-komponen non glukomanan lainnya semakin menurun (Faridah et al., 2012).

\section{Karakteristik Glukomanan}

\section{Kadar air}

Hasil yang diperoleh dari pengukuran kadar air glukomanan adalah 10,45\%. Penelitian sebelumnya yang dilakukan oleh Setiawati et al. (2017) melaporkan bahwa kadar air yang diperoleh dari glukomanan umbi porang sebesar 6,6\%. Asosiasi Konyaku Jepang (1976) mempersyaratkan kadar air glukomanan harus kurang dari $13 \%$ atau glukomanan hasil ekstraksi memenuhi standar mutu tersebut.

Menurut Rohimi \& Ninghidayati (2013), semakin tinggi suhu ekstraksi dan pengadukan maka kadar air dari tepung glukomanan akan semakin rendah dan semakin lama waktu ekstraksi maka kandungan air akan semakin banyak mengalami penguapan sehingga glukomanan lebih cepat kering. Daya simpan suatu bahan dapat bertahan lama dengan menghilangkan sebagian air yang terkandung dalam bahan hingga mencapai kadar tertentu.

\section{Kadar abu}

Kadar abu yang diperoleh dari glukomanan umbi gembili, yaitu sebesar 0,866 $\%$ atau memenuhi standar mutu dari Asosiasi Konyaku Jepang (1976), yaitu kurang dari 4,5. Hasil tersebut menandakan kadar mineral dalam glukomanan sangat rendah. Nurjanah (2010) memperoleh kadar abu glukomanan dari umbi iles-iles yaitu sebesar 3,33\%, sedangkan
Siswanti (2008) memperoleh kadar abu glukomanan dari umbi iles-iles sebesar 3,40\%.

Setiawati et al, (2017) melaporkan bahwa kadar abu glukomanan yang diperoleh dari umbi porang adalah sebesar 0,8\%. Jika dibandingkan dengan hasil penelitian Nurjanah (2010) dan Siswanti (2008), kadar abu dari glukomanan tepung umbi gembili lebih rendah. Menurut Rohimi \& Ninghidayati (2013), semakin tinggi suhu ekstraksi dan pengadukan maka kadar abu tepung glukomanan akan semakin rendah.

\section{Berat molekul}

Berat molekul glukomanan dari umbi gembili yang diperoleh adalah $1,865 \times 10^{4}$ $\mathrm{g} / \mathrm{mol}$. Hasil penelitian yang dilakukan oleh $\mathrm{Xu}$ et al. (2012) yaitu sebesar $2,508 \times 10^{5} \mathrm{~g} / \mathrm{mol}$. Polimer ataupun biopolimer yang memilki berat molekul besar, umumnya diaplikasikan sebagai bahan tambahan makanan, obat-obatan, dan perekat. Jika berat molekul polimer lebih kecil, lebih banyak dimanfaatkan sebagai antibakteri dan prebiotik.

\section{Gugus Fungsional Glukomanan}

Hasil interpretasi spektrum infra merah glukomanan, didapatkan serapan pada bilangan gelombang $3448,72 \mathrm{~cm}^{-1}$ yang merupakan vibrasi ulur gugus $-\mathrm{OH}$, sedangkan pita serapan pada bilangan gelombang $2926,01 \mathrm{~cm}^{-1}$ merupakan vibrasi ulur gugus C$\mathrm{H}$ alkana ( $-\mathrm{CH}_{3}$ atau $-\mathrm{CH}_{2}$ ). Pita serapan pada bilangan gelombang 1653,00 $\mathrm{cm}^{-1}$ menunjukkan adanya gugus $\mathrm{C}=\mathrm{O}$ (karbonil). Pita serapan gugus fungsi C-O-C (ikatan glikosidik) ditunjukkan pada bilangan gelombang 1020,34 cm $\mathrm{cm}^{-1}$, sedangkan pita serapan vibrasi tekukan gugus fungsi $-\mathrm{CH}$ terdapat pada bilangan gelombang 850,61 $\mathrm{cm}^{-}$ 1 menunjukkan (Gambar 3). Anindita et al. (2016) melaporkan bahwa vibrasi tekuk $-\mathrm{CH}$ 
dari manosa dan glukosa terlihat pada pita serapan $851 \mathrm{~cm}^{-1}$.

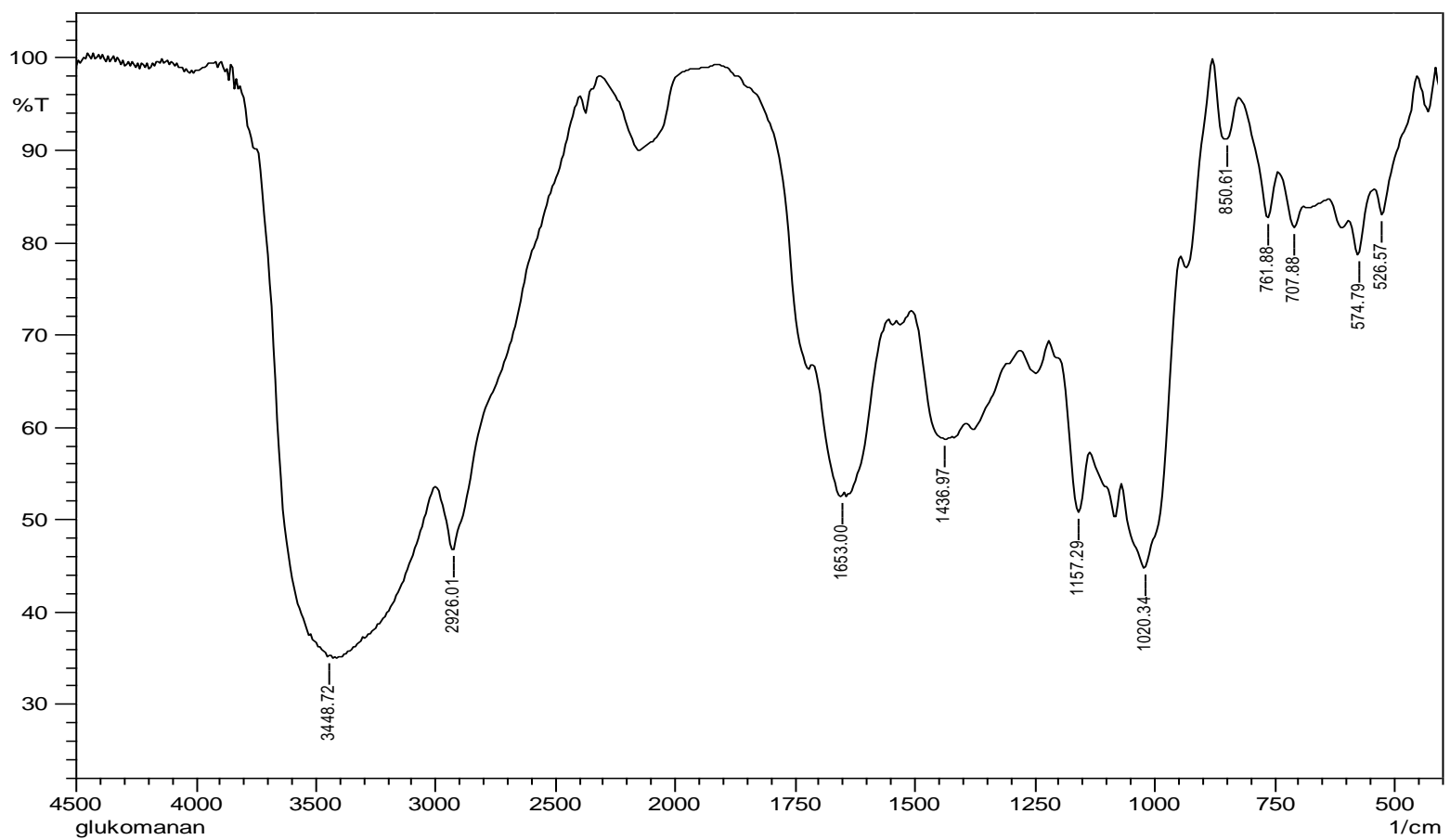

Gambar 3. Spektrum FTIR glukomanan umbi gembili.

Hasil penelitian sebelumnya yang dilakukan oleh Anindita et al. (2016), menyatakan bahwa spektra glukomanan didominasi oleh vibrasi ulur gugus fungsi $-\mathrm{OH}$ pada bilang gelombang $3431 \mathrm{~cm}^{-1}$, data ini juga didukung oleh hasil penelitian yang dilakukan oleh Irawan \& Widjanarko (2013), yaitu serapan ulur $-\mathrm{OH}$ terletak pada daerah bilangan gelombang 3438,84 $\mathrm{cm}^{-1}$. Irawan et al., (2013) melaporkan pita serapan gugus $\mathrm{C}=\mathrm{O}$ berada pada bilangan gelombang $1.647,10 \mathrm{~cm}^{-1}$. Irawan \& Widjanarko (2013) juga melaporkan bahwa pita serapan gugus $\mathrm{C}=\mathrm{O}$ pada bilangan gelombang $1647 \mathrm{~cm}^{-1}$. Hal serupa juga didapatkan oleh Anindita et al., (2016), serapan $\mathrm{C}=\mathrm{O}$ terdapat pada bilangan gelombang 1649 $\mathrm{cm}^{-1}$.

\section{KESIMPULAN}

Waktu ekstraksi glukomanan umbi gembili 90 menit dan suhu ekstraksi $105^{\circ} \mathrm{C}$ menghasilkan rendemen glukomanan tertinggi, yaitu $53,09 \%$. Kadar glukomanan umbi gembili yaitu $39,49 \%$. Glukomanan yang dihasilkan memilki kadar air 10,45\%, kadar abu 0,87\%, dan berat molekul $1,865 \times 10^{4} \mathrm{~g} / \mathrm{mol} \mathrm{g} / \mathrm{mol}$. Terdapat serapan vibrasi ulur gugus-gugus fungsi yang khas dari glukomanan, yaitu $\mathrm{C}-\mathrm{H}$ alkana $\left(-\mathrm{CH}_{3}\right.$ atau $\left.-\mathrm{CH}_{2}\right)$ pada bilangan gelombang 2926,01 $\mathrm{cm}^{-1}$ dan gugus fungsi C-OC (ikatan glikosidik) pada bilangan gelombang $1020,34 \mathrm{~cm}^{-1}$, sedangkan pita serapan vibrasi tekuk-CH terdapat pada bilangan gelombang $850,61 \mathrm{~cm}^{-1}$.

\section{DAFTAR PUSTAKA}

Akbar, H., Supriyanto, A., \& Haryani, K. (2013). Karakterisasi Tepung Konjak Dari Tanaman lles-lles (Amorphophallus oncophyllus) Di Daerah Gunung Kreo Semarang Jawa Tengah. JURNAL TEKNOLOGI KIMIA DAN INDUSTRI, 2(4), 41-47. 
Anindita, F., Bahri, S., \& Hardi, J. (2016). Ekstraksi dan Karakterisasi Glukomanan Dari Tepung Biji Salak (Salacca edulis Reinw.). KOVALEN: Jurnal Riset Kimia, 2(2), $\quad$ Article 2. http://jurnal.untad.ac.id/jurnal/index.php/ kovalen/article/view/6720

AOAC. (2005). Official Method of Analysis of The Association of Official Analytical of Chemist, Virgina, USA.

Asosiasi Konyaku Jepang. (1976). Penetapan Standarisasi Tepung Glukomanan Murni lles-lles dan Hal-hal Penting dalam Pelaksanaannya. Asosiasi konyaku Jepang. Dewan Pengurus Konyaku Tingkat Provinsi.

Faridah, A., Widjanarko, S. B., Sutrisno, A., \& Susilo, B. (2012). Optimasi Produksi Tepung Porang dari Chip Porang Secara Mekanis dengan Metode Permukaan Respons. Jurnal Teknik Industri, 13(2), 158-166.

https://doi.org/10.22219/JTIUMM.Vol13. No2.158-166

Harijati, Indriyani, N., Mastuti, S., \& Retno. (2013). Pengaruh Temperatur Ekstraksi terhadap Sifat Fisikokimia Glukomanan (Amorphallus muelleri) Menggunakan Pereaksi Dimetil Sulfat Berbagai Variasi Konsentrasi. Jurnal Pangan Dan Agroindustri, 1, 148-156.

Herlina, N. N. (2012). Produksi Pati Gembili (Dioscorea acuelata L.) Termodifikasi Dan Aplikasinya Untuk Produk Pangan [Laporan Hasil Penelitian]. FTP Universitas Jember.

Irawan, S. S., \& Widjanarko, S. B. (2013). Metilasi Pada Tepung Porang (Amorphophallus muelleri) Menggunakan Pereaksi Dimetil Sulfat Berbagai Variasi Konsentrasi. Jurnal Pangan Dan Agroindustri, 1(1), 148-156.

Nurjanah, Z. (2010). Kajian proses pemurnian tepung glukomanan dari umbi iles-iles kuning (Amorphophallus oncophyllus) dengan menggunakan enzim $\alpha$-amilase. [Skripsi]. Fakultas Teknologi Pertanian, Institut Pertanian Bogor.

Ohtsuki, T. (1967). Studies on Reserve Carbohydrates of Four Amorphophallus Species, with Special Reference to Mannan. Bot. Mag. Tokyo, 81, 119-126.

Prabowo, A. Y., Estiasih, T., \& Purwantiningrum, I. (2014). Umbi Gembili (Dioscorea esculenta L.) Sebagai Bahan Pangan Mengandung Senyawa Bioaktif:
Kajian Pustaka [In Press Juli 2014]. Jurnal Pangan Dan Agroindustri, 2(3), 129-135.

Rohimi, F., \& Ninghidayati, S. (2013). Pengaruh Temperatur Ekstraksi Terhadap Kualitas Tepung Glukomanan dari Tanaman Porang (Amorphophallus Muelleri Blume) [Skripsi]. Jurusan Teknik Kimia Institut Teknologi Surabaya.

Rukmini, P., \& Santosa, I. (2019). Pemanfaatan Pati Gembili (Dioscorea esculenta) MENJADI GLUKOSA DENGAN METODE HIDROLISIS ASAM MENGGUNAKAN KATALIS Hcl. Konversi, $8(1)$. https://doi.org/10.20527/k.v8i1.6514

Sabda, M., Wulanningtyas, H. S., Ondikeleuw, M., \& Baliadi, Y. (2019). Karakterisasi Potensi Gembili (Dioscorea esculenta L.) Lokal Asal Papua Sebagai Alternatif Bahan Pangan Pokok. Buletin Plasma Nutfah, 25(1), 25-32. https://doi.org/10.21082/blpn.v25n1.201 9.p25-32

Saputro, E., Lefiyanti, O., \& Mastuti, E. (2014). Pemurnian Tepung Glukomanan dari Umbi Porang (Amorphopallus Muelleri Blume) Menggunakan Proses Ekstraksi/Leaching dengan Larutan Etanol. Prosiding Simposium Nasional RAPI XIII-FT UMS. Simposium Nasional RAPI XIII-FT UMS, Semarang.

Setiawati, E., Bahri, S., \& Razak, A. R. (2017). Ekstraksi Glukomanan Dari Umbi Porang (Amorphophallus paeniifolius (Dennst.) Nicolson). KOVALEN: Jurnal Riset Kimia, 3(3), 234-241.

Siswanti, E. D. (2008). Komposisi kimia berbagai tepung iles-iles dan kekukuhan gel tepung iles-iles dengan variasi tambahan $\mathrm{Ca}(\mathrm{OH}) 2$ [Skripsi]. Fakultas Teknologi Pertanian UGM.

Tatirat, O., \& Charoenrein, S. (2011). Physicochemical properties of konjac glucomannan extracted from konjac flour by a simple centrifugation process. LWT - Food Science and Technology, 44(10), 2059-2063. https://doi.org/10.1016/j.Iwt.2011.07.019

Towaha, J., \& Rusli. (2016). Diversifikasi Pemanfaatan Senyawa Glukomannan lles-lles. SIRINOV, 4(1), 1-10.

Widjanarko, S. B., \& Megawati, J. (2015). Analisis Metode Kolorimetri Dan Gravimetri Pengukuran Kadar Glukomanan Pada Konjak 
(Amorphophallus konjac) [In Press September 2015]. Jurnal Pangan Dan Agroindustri, 3(4), Article 4. https://jpa.ub.ac.id/index.php/jpa/article/v iew/283

Wigoeno, Y. A., Azrianingsih, R., \& Roosdiana, A. (2013). Analisis Kadar Glukomanan Pada Umbi Porang (Amorphophallus muelleri Blume) Menggunakan Refluks Kondensor. Biotropika: Journal of Tropical Biology, 1(5), 231-235.

Xu, M., Li, D.-S., Li, B., Wang, C., Zhu, Y.-P., Lv, W.-P., \& Xie, B.-J. (2012). Comparative Study on Molecular Weight of Konjac Glucomannan by Gel Permeation Chromatography-Laser Light Scattering-Refractive Index and Laser Light-Scattering Methods. Journal of Spectroscopy, 2013, 1-4. https://doi.org/10.1155/2013/685698 